\title{
Medical Waste Storage Practice in Health Care Institutions of Pokhara Sub-metropolitan City
}

\author{
Banstola D', Banstola R², Nepal D³, Baral P4* \\ 'Associate Professor, Physiology Department, Institute of Medicine, Maharajgunj, Kathmandu, Nepal \\ ${ }^{2}$ Associate Professor, Institute of Engineering, Pashchimanchal Campus, Lamachaur, Pokhara, Kaski, Nepal \\ ${ }^{3}$ Associate Professor, National Academy of Medical Sciences, Kanti Children Hospital, Kathmandu, Nepal \\ ${ }^{4}$ Professor, Anatomy Department, Gandaki Medical College \& Teaching Hospital, Pokhara, Nepal
}

\section{Keywords \\ Health care institutions, Medical waste, Pokhara sub-metropolitan city. \\ Corresponding author \\ *Dr. Prakash Baral \\ Professor, Anatomy Department, Gandaki Medical College \& Teaching \\ Hospital, Pokhara, Nepal \\ Email: prakashbaral2002@hotmail.com}

\begin{abstract}
Introduction: Medical wastes include all the waste generated by health care establishments, research facilities, and laboratories. Medical waste is any waste that is generated in the diagnosis, treatment or immunization of human beings or animals, in research pertaining there to or in the productions or testing of biological culture.
\end{abstract}

Methods: The fourteen numbers of health care institutions (HCIs) having inpatient facilities, were sampled for the study. After taking observation, the collected information was entered into a computer. Basically, the percentages, projection analysis, simple average, and scenario analysis were used as an analysis tools.

Results: Out of the HCIs surveyed, only $21.43 \%$ of them had a separate room assigned for primary storage of all sorts of waste and remaining $78.57 \%$ of them had open storage facilities for un-segregated mass of waste nearby the incineration area or open burning area.

Conclusion: There was lack of appropriate information on waste storage practices, and unaware of designing central storage system in HCIs. In most of the HCIs, a separate storage room was not assigned for storage of all sorts of waste.

\section{INTRODUCTION}

WHO mentioned, medical wastes includes all the waste generated by health care establishments, research facilities, and laboratories. Medical waste is any waste that is generated in the diagnosis, treatment or immunization of human beings or animals, in research pertaining there to, or in the productions or testing of biological culture.

Environment and development are the two sides of the same coin yet, the impact of development on environment is very nominal if their dimension is same. A good environment is necessary for healthy living. Contrary to this fact, people are facing various problems regarding health, environment, and sanitation due to poor management of health care waste. The major portion of waste generated in health care activities consists of general waste that can be treated in the same way as domestic or municipal waste; therefore not all of health care wastes are harmful, and hazardous. This remains true only when proper segregation and separation of waste is practiced according to type at the source. Health care waste can be a source for transmission of infectious diseases like AIDS, hepatitis $\mathrm{B}$, hepatitis $\mathrm{C}$, tetanus, diarrhea, tuberculosis, cholera, and as well as serious environmental problems in 
terms of air, water and soil pollution, whenever handled improperly ${ }^{1-3}$.

\section{OBJECTIVES}

The main objective of this research is to study the present practices of medical waste storage in health care institutions in PSMC.

\section{METHODS}

The fourteen numbers of health care institutions (HCIs) having inpatients facilities, were sampled for the study. Out of 14 HCIs, one community hospital, one Government hospital, one NGO run hospital, one INGO run hospital, one nursing home, eight private hospitals and one teaching hospital were surveyed for the study.

After taking observation, the collected information was entered into computer. Basically, the percentages, projection analysis, simple average, and scenario analysis were used as an analysis tools.

\section{RESULTS}

Out of the HCIs surveyed, only $21.43 \%$ of them had a separate room assigned for primary storage of all sorts of waste, and remaining $78.57 \%$ of them had open storage facilities for un-segregated mass of waste nearby the incineration area or open burning area allowing easy access to birds, and other scavenger. This open mass storage practices could cause air/water pollution as well as risk of spreading epidemic diseases. Those HCIs having storage room were provided with facilities like, impermeable floor, good drainage, and easy to clean surface where as water supply was poor, no provisions of warning signs, and the area was not protected against rodents, insects, and birds.

Waste storage facilities available in health care institutions (HCIs) in pokhara sub-metropolitan city (PSMC) are given in Table 1.

Table 1: Waste Storage Facilities Available in HCIs

\begin{tabular}{ccc}
\hline $\begin{array}{c}\text { Availability of waste } \\
\text { storage room }\end{array}$ & No & Percentage \\
\hline Yes & 3 & $21.43 \%$ \\
No & 11 & $78.57 \%$ \\
Total & $\mathbf{1 4}$ & $\mathbf{1 0 0 \%}$ \\
\hline
\end{tabular}

Fig 1: Waste storage facilities available in HCIs

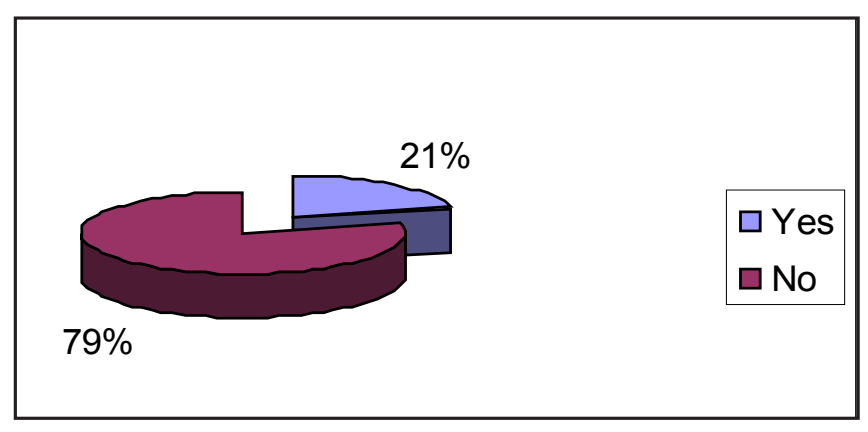

Out of HCIs surveyed, only $21.43 \%$ of them were segregating their waste in storage area, and rest $78.57 \%$ were not segregating any sort of waste in storage area. This may cause problem while incinerating the infectious waste. The waste storage period was not fixed and defined, which depend upon municipality services in most of the HCIs. Segregation of waste in storage area is presented in Table 2.

Table 2: Segregation of waste in storage area

\begin{tabular}{ccc}
\hline $\begin{array}{c}\text { Waste segregation } \\
\text { practiced }\end{array}$ & $\begin{array}{c}\text { No of } \\
\text { HCIs }\end{array}$ & Percentage \\
\hline Yes & 3 & $21.43 \%$ \\
No & 11 & $78.57 \%$ \\
Total & $\mathbf{1 4}$ & $\mathbf{1 0 0 \%}$ \\
\hline
\end{tabular}

Fig 2: Segregation of waste in storage area

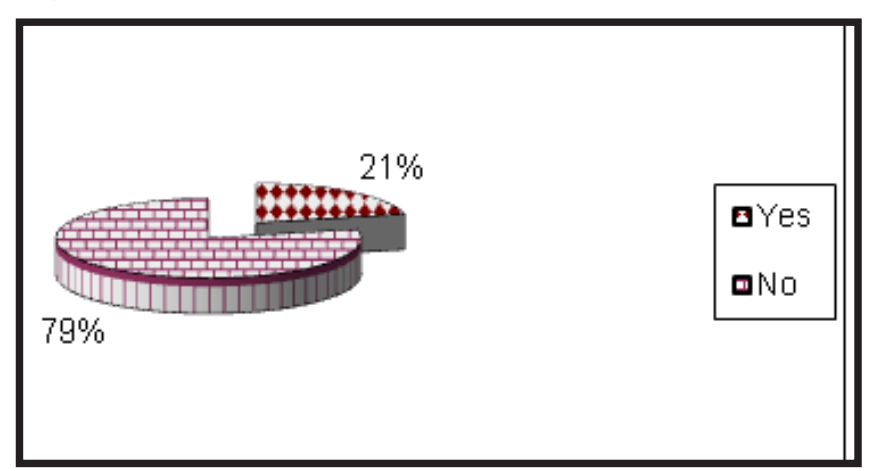

The time period of disposal of segregated waste after storage in HCIs is given in Table 3.

Table 3: Time period of disposal of segregated waste in HCIs

\begin{tabular}{ccc}
\hline Time period of disposal & No of HCIs & Percentage \\
\hline Within $24 \mathrm{hrs}$ & 5 & $35.71 \%$ \\
$24 \mathrm{hrs}-48 \mathrm{hrs}$ & 3 & $24.43 \%$ \\
$48 \mathrm{hrs}-72 \mathrm{hrs}$ & 1 & $7.14 \%$ \\
Municipal services & 5 & $35.71 \%$ \\
Total & $\mathbf{1 4}$ & $\mathbf{1 0 0 \%}$ \\
\hline
\end{tabular}


Among the surveyed HCIs, time period of disposal of segregated waste in HCIs was found $35.71 \%$ within 24 hours, $21.43 \%$ within 24 hours - 48 hours, $7.14 \%$ within 48 hours -72 hours, and rest $35.71 \%$ rely on municipal services. Storing of waste for longer period can lead the spread of disease as well as production of offensive smell where as access to scavengers in case of open storing.

\section{DISCUSSION}

There is no proper and scientific health care waste storage system due to the lack of awareness, accountability from actors in health care waste management, and well elaborated control mechanisms presently reigning in almost all the HCIs in the PSMC. The current medical waste storage practices of hospital solid waste does not guarantee the risk to environment and public health. Health care waste generated from the HCIs should be properly stored to avoid the hazards on health, and environment.

In present study, out of the HCIs surveyed, only $21.43 \%$ of them had a separate room assigned for primary storage of all sorts of waste, and remaining $78.57 \%$ of them had open storage facilities for un-segregated mass of waste nearby the incineration area or open burning area allowing easy access to birds, and other scavenger. This open mass storage practices could cause air/water pollution as well as risk of spreading epidemic diseases. Those HCIs having storage room were provided with facilities like, impermeable floor, good drainage, and easy to clean surface where as water supply was poor, no provisions of warning signs, and the area was not protected against rodents, insects, and birds.

The segregation of waste in storage area was not practiced in most of the HCIs. Out of HCIs surveyed, only $21.43 \%$ of them were segregating their waste in storage area, and rest $78.57 \%$ were not segregating any sorts of waste in storage area. This may cause problem while incinerating the infectious waste. The waste storage period was not fixed and defined, which depend upon municipality services in most of the HCIs.
From this review, it can be concluded that concerned health care institutions does not have any policies, legislation and technical guidelines to guide and regulate hospital solid waste storage. In future, there should be integrated waste management system and centralized waste management system within HCIs with uniform standards and policies under health care waste management act, which may need to be planned and implemented to solve the gravity of problems ${ }^{4-6}$.

\section{CONCLUSION}

There was lack of adequate information on waste storage practices, and unaware of designing central storage system in HCIs. In most of the HCIs, a separate storage room was not assigned for storage of all sorts of waste.

\section{REFERENCES}

1. Park K. Park's Textbook of Preventive and Social Medicine. M/S Banarsidas Bhanot Publishers, India. Eighteenth Edition 2005; 595-599.

2. WHO. Health Care Waste Management: Policy Paper, August 2004. http:// www. healthcarewaste.org/en/520-regul-national. html

3. WHO. Management of Solid Health Care Waste at Primary Health Care Centers: A Decision Making Guide. WHO, Geneva, 2004. http:// www.who. int/topics/medical-waste/en/

4. Akter N. Medical waste management: A review. AIT, Thiland. January 2000; 124-130.

5. Hinshaw GD, Trenholm AR. Hazardous waste incineration emission in perspective. Waste management. 2001; 21: 471-475.

6. Philips PS, Pratt R.M, Pike K. An analysis of UK waste minimization clubs: Key requirements for future cost effective developments. Waste management. 2001; 21: 389-404. 